the report is offered as a means of providing "universities with a means of comparing their use of capacity with others". It remains to be seen whether the project will have more to say, in the years ahead, about the ways in which universities should manage their affairs, but the report says that the next step is to estimate what savings and qualitative improvements would be possible "if optimal patterns of use are adopted". Eventually, the argument runs, the universities would then be more able to formulate accurate plans for capital expenditure. The report also looks forward to a kind of advisory service equipped to keep a continuously watchful eye on university practices and able to offer advice about the ways in which universities might get better value for money.

Mr Davies explained, earlier this week, that there is not yet a tangible plan for setting up a continuing organization to superintend the ways in which universities make use of their facilities. The progress report which has now been issued says very little about British university practice in present circumstances, but there is a brief statement that, in the universities already surveyed, the "occupancy factor" of teaching rooms works out at 75 per cent, which is "no mean performance" compared with the average occupancy of 30 hours a week out of 45 in the universities of Washington and California. This brief statement is, of course, quite unconvincing without supporting evidence and has on this account provoked some sarcasm in the daily newspapers. Mr. Davies explained during the week that more detailed information had been circulated to the committee of vice-chancellors, though it is not yet clear whether this is already being used for purposes of comparison by British universities. $\mathrm{He}$ emphasized that his enquiries were only at a preliminary stage and explained that in any case the details of his work would not be understandable "to people outside the universities".

\section{Landing Sites on the Moon}

THE National Aeronautics and Space Administration (NASA) has completed its selection of landing sites on the Moon for the Apollo astronauts. Five areas, each three by five miles in size, have been chosen by the Apollo Site Selection Board, it was announced last week. Site selection has been achieved through the photographic survey carried out by the Lunar Orbiter series of spacecraft reinforced by the spot checks of the Surveyor landers. At the beginning of the survey programme thirty tentative sites ranged along the Moon's earthward face were under consideration. The observations of the survey spacecraft reduced these to eight "possibles". From these, the board has selected the five target sites and the Apollo men will leave for their mission not knowing which of three they will use.

All five sites lie within a quite narrow band along the lunar equator-within $45^{\circ}$ east and west of the visible Moon's centre and $5^{\circ}$ of the equator, the socalled Apollo Zone of Interest, where optimum conditions for communications and surveillance from Earth of the astronauts' progress exist. Two are in the Sea of Tranquillity, one in the Central Bay, and two in the Ocean of Storms (Mare Tranquillitatis, Sinus Medii, Oceanus Procellarum). Apart from this, each site has had to satisfy seven other criteria necessary for the safety of astronauts. These are relative freedom from craters and boulders; a smooth approach path without large hills, cliffs or deep craters likely to cause inaccurate altitude signals on the landing radar; a slope of less than $2^{\circ}$ over the landing site and approach path; central grouping enabling the least. expenditure of propellant by the lunar module; optimum visibility for the approaching astronauts in guiding their eraft down. which requires that the Sun angle should lie between $7^{\circ}$ and $20^{\circ}$ and come from behind the craft at landing. This last criterion gives a 1-day launch window each month. The intervals between the sites have had to correspond with the time needed to re-cycle the Apollo/Saturn $\mathrm{V}$ if there is a check during initial countdown; and, finally, site location must be within reach of the Apollo "mothership" on a free-return trajectory, that is, where the spacecraft can coast round the Moon and return to Earth without employing propulsion. Altogether this will make a 3-day period each month available for launching the first Apollo flight.

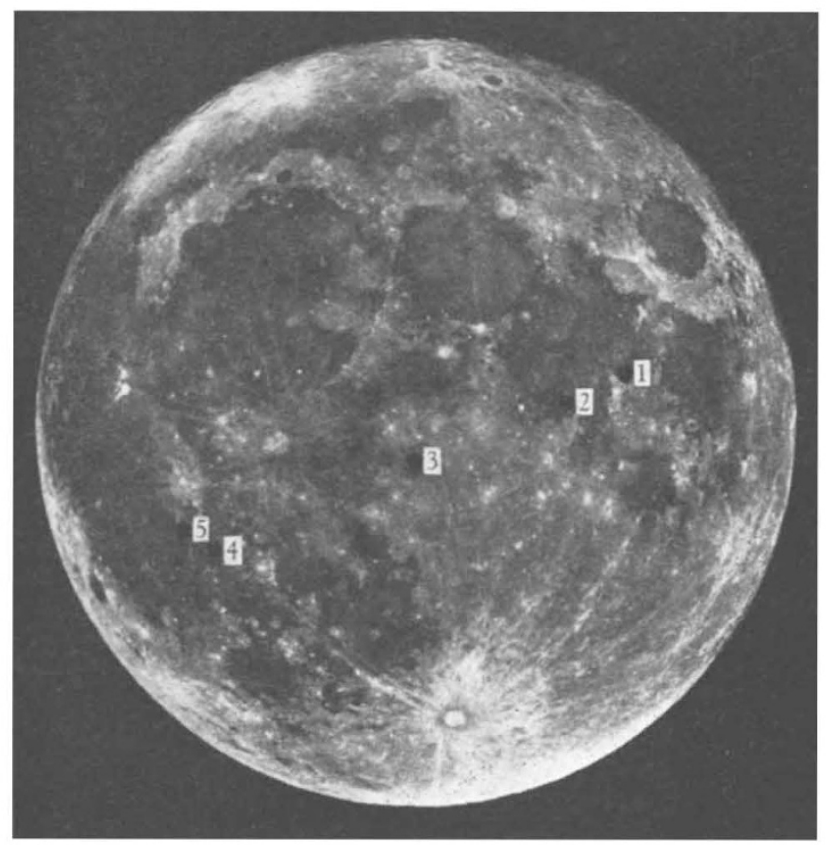

The five sites chosen for the Apollo landing are in the Mare Tranquillitatis (I) and (2), the Sinus R.edii (3), and the Oceanus Procellarum (4) and (5).

\section{Contraception in France}

General DE GaULLE's dream of a French population of one hundred million by the end of the century is not likely to be greatly thwarted by a new French law on contraception, passed on December 19, 1967. Although this law, the Neuwirth law, may well serve to make contraception more respectable, it is in many ways unsatisfactory and has been widely criticized.

The history of events leading up to the formulation of the law reflects the absurdity of the situation. After the First World War, possibly because many Frenchmen had been killed, a notorious law was passed which made contraception illegal. Since then the only method of contraception to which the authorities have turned a blind eye has been the condom, which has come to be regarded as a prophylactic against venereal disease rather than as a contraceptive. 
Various forms of oral contraceptives have been available in France for several years because of their initial therapeutic role, but not everyone can afford them.

The family planning association called the Mouvement Français pour le Planning Familial (MFPF) has, however, been operating "underground" and has until recently got around the law by running the organization on the lines of a club with paying members. The organization now has a membership of 100,000 and has more than three hundred centres.

According to the new law, decisions about the manufacture and importation of contraceptives will be subject to a ruling by the public authority, and the sale of contraceptive products will be subject to an authorization of the Minister of Social Affairs. The sale of such articles will be confined to chemists' shops, while those oral contraceptives placed on the so-called "special list" will only be sold under prescription; and the doctors concerned will be required to consider the patients' medical history. Minors up to 18 years old under parental control requiring contraceptives, and similar young people up to 21 years old requiring oral contraceptives on the special list, will have to have a prescription as well as the written consent of a parent or legal guardian.

Under the new law, family planning associations will not be allowed to supply contraceptives as they have done in the past. Another blow to such organiza. tions is that all "antinatalist propaganda" will be forbidden, which means that people seeking advice from an association will have no means of finding it, either from advertisements, or, presumably, from telephone directories. The government intends to back up the law with fines and imprisonment for offenders.

Because the Social Security will not have to reimburse the costs of progesterones, as it does the cost of other medicines, some doctors contend that it is the poor who will suffer most. There is also a feeling that the law places too much responsibility on the doctors, allowing them to interpret it according to their moral and religious principles. Others feel that it is intolerable that patients should be so closely controlled in so personal a matter. One objector on medical grounds, Professor Jacques Huguier, has suggested that, if the law is not repealed before it comes into action on March 1, wholesale resignation of the medical profession might be called for. An extremist's view, perhaps, but it is evidence of the kind of opposition the law is meeting.

\section{More European Physics}

The plan for forming a European Physical Society has been modified somewhat in the light of the discussions of the steering committee which met on January 30 at the Battelle Institute in Geneva. For one thing, it has bcen decided to postpone the large conference which had first been hoped to inaugurate the society at Florence in September this year. This event will not now take place until 1969. Instead there will be an inaugural ceremony in Geneva in September this year. At the same time it appears that serious discussions have been opened with a number of countries from Eastern Europe-Yugoslavia, Czechoslovakia, Hungary and Rumania. Although the representatives of the physical societies in these countries have been given clearly to understand that the formation of a European Physical Society will not be obliged to allow them to determine their own relationship to it, there does now seem hope that they will eventually be associated with the work at some stage. In the meantime, it appears that there have emerged a number of difficulties about the financial provisions in the constitution although these will most probably be resolved at the next meeting of the steering committee due to be held in the spring this year. With luck this will be held in Prague, but otherwise in Vienna.

It has been agreed that the headquarters of the society will be in Geneva at the physics department of the university, 32 Boulevard d'Yvoy, 1211 Geneva 4. It has also been agreed that the working language of the society will be English. At the meeting on January 30 it was agreed that the European Chemical Society should publish a bulletin, principally to keep European physicists informed about the discussions now going on, but there seems some confusion about the way in which this will be accomplished. In the circumstances, it is not surprising that the steering committee has not yet had a chance to take up the more complicated question of how to organize the learned journals in physics which cater for European scientists. The first inclination seems to be to divide physics as a whole into fields which could be parcelled out to the journals which already publish original articles in physics, and in this spirit existing publishers are likely to be approached in the next two weeks. It would not, however, be surprising if in the end the European Physical Society decided to follow a more informal and more empirical course, if only for the sake of the flexibility it would thereby gain.

\section{New Hope for Planning}

THe first rumblings of a new assault on national planning were heard last week when Mr Peter Shore, Secretary of State for Economic Affairs, presented a Government paper to a meeting of the National Economic Development Council. It appears that few details were given at the meeting, but it was stated that another paper would be presented after the budget on March 17, with broad outlines of the way the economy should develop. The economic development councils for the different sectors of industry will then be able to discuss the projections and work out what the effects will be on their own sections of industry. There are twenty-one councils, known affec-

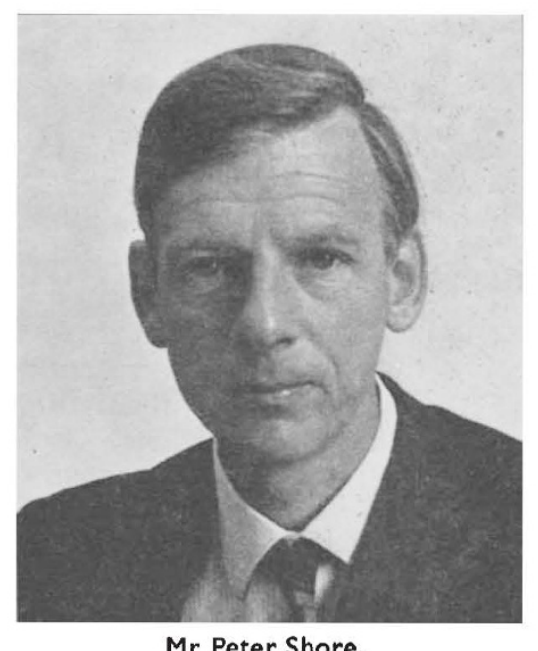

Mr Peter Shore. 